\title{
The specifics of forming a strategy for sustainable development of the regional agro- industrial complex
}

\author{
Natalia Shvydenko ${ }^{1}$, Oxana Ananova ${ }^{1, *}$, and Irina Sokolova ${ }^{1}$ \\ ${ }^{1}$ Don State Technical University, pl. Gagarina, 1, Rostov-on-Don, 344003, Russia
}

\begin{abstract}
The article deals with the problem of sustainable concept development of the regional agro-industrial complex (AGC). A reasonable and objective approach to this problem using the knowledge of regularities of socio-ecological-economic systems development and the study of divergent environmental factors and internal environment enables developing effective management decisions of strategic and tactical nature of the selection tools sustainable agriculture development. The formal presentation of the agro-industrial complex's main stability characteristics allows providing a comprehensive assessment of its condition to justify a particular structural model of the sustainable development strategy of AGC with changes in the level of exposure to environmental parameters.
\end{abstract}

\section{Introduction}

One of the implementation concept elements of sustainable development is integrating Russian agriculture into the international economic relations system [2], which is impossible to implement soon for several reasons. Firstly, falling into a rut from the previous development (path dependence paradox), Russia, due to limited access to modern financial institutions and tools, cannot be involved in the game with new "sustainable requirements". Secondly, the technological vacuum due to the extreme wear and tear and moral ageing of fixed assets, the unfavorable structure of the economy, outdated technologies and low legal culture becomes a real obstacle $[1,2]$.

Implementing the sustainable agriculture concept is possible only in a closed-cycle economy, and this model does not correspond to the modern Russian reality. The situation is complicated by the lack of sufficient programs to support innovations in agriculture and their weak practical implementation at the regional and federal levels $[3,4]$.

The solution of this problem is possible only by forming long-term systematic state planning and creating such conditions and factors that will contribute to a rapid and highquality transition to a sustainable model of the economy, including in the agro-industrial complex.

\footnotetext{
*Corresponding author : o_ananova@mail.ru
} 


\section{Materials and methods}

Since the mid-1990s, the share of agriculture in GDP has reduced by half. In 2018, it was about $3.5 \%$. At the same time, about $15 \%$ of Russia's territory is in an environmentally unsatisfactory state [1]. Also, the country's agroclimatic conditions' peculiarities determine the territorial limits for sustainable and productive agricultural farming, and the specific indicators of environmental impact per capita and per unit of gross national product are at a low level. The lag of the agro-industrial complex has become chronic, and for the transition to" sustainability" it is necessary not only to develop an effective strategy for implementing taken decisions but also to transform it into systematic practical measures.

Currently, there is a growing trend in Russia that the concept of "sustainable agriculture" is interwoven into the business strategies of large companies in the agricultural sector, and the declaration of commitment to the goals of "sustainable development" becomes a tool for promoting projects, innovative solutions and initiatives.

The fundamental document in the field of promoting the sustainable development of agriculture in Russia is the "Food Security Doctrine of the Russian Federation", an updated version which was approved in 2020 .

The following programs provide mechanisms for creating sustainable production systems and financial support: "State Program for the development of agriculture and regulation of markets for agricultural products, raw materials and Food", "Federal Scientific and Technical Program for the Development of Agriculture for 2017-2025", "Strategy for Sustainable development of rural areas of the Russian Federation for the period up to 2030". To ensure the sustainable development of food production in Russia, several sectorial strategic programs are being implemented at the state level. However, the state's role is limited to stimulating individual organizations and the lack of programs effectiveness $[5,6]$.

In connection with the ongoing changes in internal and external factors, the emergence of material and spiritual needs of the population, with new requirements for the quality of a modern person's life, the search for effective methods of long-term strategic management and ways of socio-economic development of the region in terms of costs minimizing and rational use in the space-time continuum becomes an urgent task particularly.

Over the past decade, scientific works have proved that the most appropriate is to use institutional-synergetic, systemic and integrated approaches in the study of the theoretical aspects of the sustainable development of the territories' economy. It should be noted that the category of "sustainable development" is considered at the levels of economic activity: international, national, regional and the level of an individual enterprise.

The specifics of the strategy formation for the sustainable development of the regional agro-industrial complex are the special importance of production issues, economic and financial nature, socio-economic development problems, activation of innovation policy, and ensuring food and environmental safety.

The methodological basis for the sustainable development of the regional agro-industrial complex consists of two components of long-term planning:

- the concept of sustainable development as a key priority (the 2030 Agenda for Sustainable Development, adopted at the United Nations Conference in 2015);

- the strategy as a strategic planning tool based on coordination with similar programs being developed or already being implemented at the federal and regional levels of government. 


\section{Results}

The analysis of existing problems in the agricultural sector and their connection with the sustainable development of goals and targets of Agenda 2030 allowed identifying the most relevant challenges for the agricultural-food sector of the Russian economy:

- elimination of hunger and sustainable agriculture,

- decent work and economic growth,

- responsible consumption and production,

-conservation of marine ecosystems and conservation of terrestrial ecosystems.

The key aspects of the institutional-synergetic approach to the sustainable development of the agro-industrial complex are the necessity to coordinate all factors by forming coordinated goals for economic and financial institutions and technopolises that combine scientific, industrial, financial and entrepreneurial capital into a single system-cluster structure. Therefore, achieving a synergistic effect is possible only when the factors of sustainable development interact on the basis of balanced interests between the government agencies, business structures and the population. This approach allows the regional socioecological and economic system to resist negative external influences and increase its readiness for strategic changes [7-9].

Along with the creation of conditions for rapid adaptation to changing factors, the main prerequisite for the sustainable development of the agro-industrial complex is the economic relations between the entities that make management decisions and contribute to the continuous process of effective functioning of the regional economy in the long term $[4,5,10,11]$. Based on well-known laws, principles, and regional management methods, the authors formulate a general model of the organizational and economic mechanism for the sustainable development of the regional agro-industrial complex (Figure 1).

The greatest scientific interest from the point of view of forming a strategy for the sustainable development of the regional agro-industrial complex is a block that includes applied tools that would allow developing key measures to reorganize the structure of the agricultural sector and ensure overcoming negative manifestations of the Russian economy crises in order to minimize their consequences (table 1). 


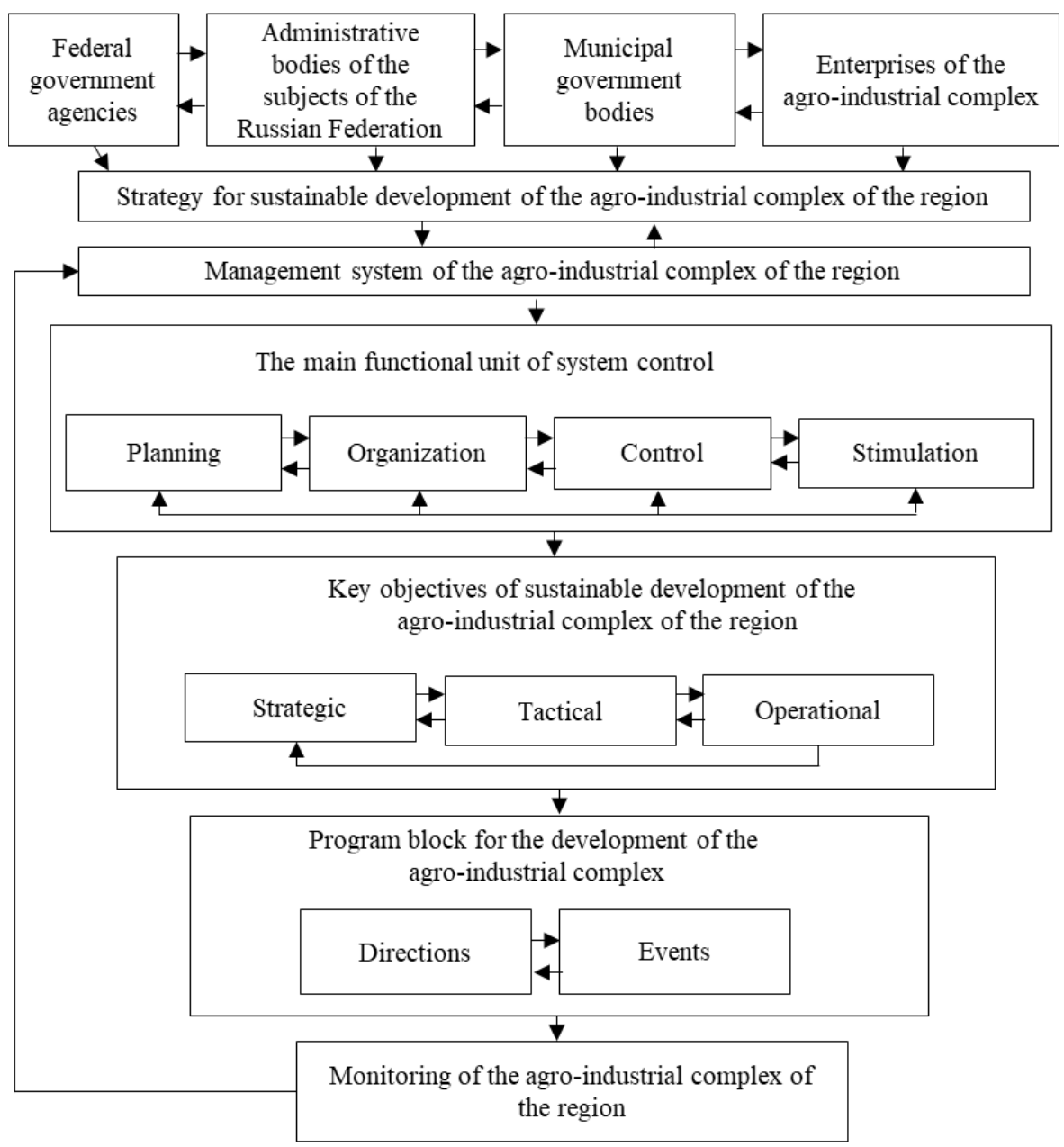

Fig. 1. General model of the organizational and economic mechanism of sustainable development of the regional agro-industrial complex.

Table 1. Stages of implementation of the strategy for sustainable development of the regional agroindustrial complex.

\begin{tabular}{|l|l|}
\hline $\begin{array}{l}\text { 1. Preparatory } \\
\text { stage }\end{array}$ & $\begin{array}{l}\text { - development of targets for the sustainable development of the agro- } \\
\text { industrial complex at the federal and regional levels; } \\
\text { - development of measures set aimed at the regulatory, organizational, } \\
\text { scientific, personnel and software support of the regional agro-industrial } \\
\text { complex structure }\end{array}$ \\
\hline $\begin{array}{l}\text { 2. Experimental } \\
\text { stage }\end{array}$ & $\begin{array}{l}\text { - objective assessment of the state and analysis of the agro-industrial complex } \\
\text { problems; } \\
\text { - - identification of trends in the development of the agro-industrial complex at } \\
\text { various levels of territorial administration; } \\
\text { - conducting a final SWOT analysis to } \\
\text { determine the strengths and weaknesses of the agro-industrial complex, assess } \\
\text { the prospects and opportunities for its development, and draw conclusions } \\
\text { about the feasibility and nature of the measures; } \\
\text { - development of alternative scenarios for the development of the regional } \\
\text { agro-industrial complex; }\end{array}$ \\
\hline
\end{tabular}




\begin{tabular}{|c|c|}
\hline & $\begin{array}{l}\text { - clear formulation of the final mission, strategic goals and objectives for the } \\
\text { sustainable development of the regional agro-industrial complex }\end{array}$ \\
\hline $\begin{array}{l}3 . \\
\text { analysis }\end{array}$ & $\begin{array}{l}\text { - application of economic and mathematical modeling methods and } \\
\text { forecasting of dynamic processes to ensure qualitative and quantitative results } \\
\text { due to the high capital and resource intensity of the agro-industrial complex; } \\
\text { - forecast of achieving a positive social effect by increasing the real income } \\
\text { of the population, improving the quality of human life and the quality of social } \\
\text { infrastructure, reducing the outflow of rural population to cities; } \\
\text { - search for sources of financing for the developed strategy of sustainable } \\
\text { development of the agro-industrial complex, identification of additional } \\
\text { possible sources of resources (financial, labor, material, etc.); } \\
\text { - assessment of possible risks and development of measures to prevent them; } \\
\text { - the process of promoting the sustainable development of the agro-industrial } \\
\text { complex through the organization and presentation of the developed strategy } \\
\text { at different levels-at the federal, regional, etc. }\end{array}$ \\
\hline $\begin{array}{l}4 . \\
\text { Implementation } \\
\text { stage }\end{array}$ & $\begin{array}{l}\text { Implementation of measures in accordance with the: } \\
\text { - conceptual directions of sustainable development; } \\
\text { - principles of activation of innovation policy in the regional agro-industrial } \\
\text { complex; } \\
\text { - sufficient resources from the federal and municipal budgets, from the funds } \\
\text { of domestic and foreign investors, etc. }\end{array}$ \\
\hline $\begin{array}{l}\text { 5. Monitoring of } \\
\text { results }\end{array}$ & $\begin{array}{l}\text { - evaluation of the indicators of the departmental strategy for the development } \\
\text { of the regional agro-industrial complex as target indicators; } \\
\text { - formation of specific indicators system in the regional agro-industrial } \\
\text { complex, reflecting the nature of changes and the degree of their impact on its } \\
\text { external and internal environment; } \\
\text { - conducting regular monitoring to make adjustments to the strategy and } \\
\text { monitoring of resources adequacy for the implementation of the goals; } \\
\text { - calculation of the strategy effectiveness for sustainable development of the } \\
\text { agro-industrial complex }\end{array}$ \\
\hline
\end{tabular}

The strategy of sustainable development of the regional agro-industrial complex is a set of separate elements of operational, medium-and short-term planning and is based on the principle of its implementation continuity [5,6,11]. As a result, public authorities maximize the effectiveness of the sustainable development strategy of agriculture by conducting regular monitoring with the aim of making the necessary adjustments and controls sufficient resources to achieve its goals [12].

Ultimately, the implementation of the agro-industrial complex's sustainable development strategy should help maximize the income received by the participants of the processes, which should ensure stable economic growth, food, and economic security of the state.

\section{Discussion}

The practice shows the imperfection of integration and cooperation to solve the problems of sustainable development of the region's agro-industrial complex. During the development of sustainable development strategy of regional agriculture, it is necessary to consider the multiplier effect's occurrence, as the innovation policy helps develop other sectors of the economy, the level and the quality of life of the population. This approach also allows us to coordinate the planned strategic goals of sustainable development of other regional economic systems and neutralize the irrational use of resources, including budget funds [13]. 
The regional strategy of agriculture development should provide the structural deformation of the regional agro-industrial complex, tailored to suit the territorial APK characteristics and make maximum use of its potential in terms of costs rationalization for the implementation of its strategic development directions [5,14].

The modified methodological approach proposed by the authors for building a sustainable development strategy (conceptual aspect) and strategic planning of the regional agroindustrial complex for the long term (applied aspect) allows us to justify the need to choose a rational organizational and economic mechanism for implementing the strategic program for sustainable development of the agro-industrial complex, taking into account some possible risks and threats.

\section{Conclusions}

Promising areas for further research will be an in-depth analysis of existing programs for the development of the agricultural-food sector, comparing them with the global sustainable development goals and objectives to identify inconsistencies and opportunities for changes, as well as improving and developing specific indicators for monitoring and evaluating progress in the development of the regional agro-industrial complex.

The direction for future research is of scientific interest and will require a further interactive tool, synthesizing statistical data to develop a specific system of indicators for measuring agriculture's sustainability at the national and regional levels.

In the future, the strategy of agriculture development in the region should be based on the study of the process of creating a unified system-cluster structure of agricultural production that will identify the missing stages, to eliminate redundant subsystems and improve the competitive advantages of agricultural production, in particular, and regional AG complex as a whole.

\section{References}

1. N.I. Ivanov, T.V. Shevchenko, V.S. Gorbunov, Journal of agronomy and animal industries 14(4), 520-558 (2019) https://doi.org/10.22363/2312-797X-2019-14-4-520558

2. O. Takhumova, E3S Web of Conferences 208, 03043 https://doi.org/10.1051/e3sconf/202020803043

3. S. Bila, University Economic Bulletin 45 (2020) https://doi.org/10.31470/2306-546X2020-45-7-21

4. I. Buzko, O. Vartanova, I. Trunina, I. Khovrak, SHS Web of Conferences 61, 01001 (2019) https://doi.org/10.1051/shsconf/20196101001

5. V.S. Vasilyeva, Economic Consultant 30, 2 https://doi.org/10.46224/ecoc.2020.2.3

6. S. Ugrimova, N. Andreeva, T. Tuchkanen, E3S Web of Conferences 175, 06003 (2020) https://doi.org/10.1051/e3sconf/202017506003

7. Y.V. Mochalova, I.V. Korsakova, Journal of Volgograd State University 37, 140-146 (2016) https://doi.org/10.15688/jvolsu3.2016.4.12

8. D.V. Zavyalov, O.V. Saginova, N.B. Zavyalova, Innovation Development 9, 1 (2018) https://doi.org/10.18184/2079-4665.2018.9.1.123-136

9. S. Drobyazko, V. Okulich-Kazarin, A. Rogovyi, O. Goltvenko, S. Marova, Strategy Management of Corporations Academy of Strategic Management Journal 18, 1 (2019) 
10. N. Gerasymchuk, Modern management review XXIV(4) (2020) https://doi.org/10.7862/rz.2019.mmr.26

11. T. Bogdanova, M. Karlik, International Journal of Technology 11(8), 1478-1488 (2020) https://doi.org/10.14716/ijtech.v11i8.4531

12. R.O. Tolstolutsky, Proceedings of the Voronezh State University of Engineering Technologies 82(2), 234-242 (2020) https://doi.org/10.20914/2310-1202-2020-2-234242

13. I. Voiku, G. Varlamov, E3S Web of Conferences 112, 03015 (2019) https://doi.org/10.1051/e3sconf/201911203015

14. R.P. Belolipov, S.N. Konovalova, M.V. Zagvozkin, Proceedings of the Voronezh State University of Engineering Technologies 80(2), 407-414 (2018) https://doi.org/10.20914/2310-1202-2018-2-407-414 